\title{
Adoletras: Um jogo de Realidade Aumentada para auxiliar no processo de Alfabetização
}

\author{
Tatyane Souza Calixto da Silva ${ }^{1}$, Amanda Souza Calixto da Silva ${ }^{2}$, Jeane Cecília \\ Bezerra de Melo $^{3}$
}

${ }^{1}$ Centro de Informática - Universidade Federal de Pernambuco (UFPE)

Av. Prof. Moraes Rego, 1235 - Cidade Universitária Brazil - CEP: 50670-901 - Recife PE Brasil

\author{
${ }^{2}$ Comunicação Visual - Escola Técnica Estadual Miguel Batista \\ Av. Norte Miguel Arraes de Alencar, 7487 - Apipucos, Recife - PE, 52071-470 \\ ${ }^{3}$ Departamento de Estatística e Informática - Universidade Federal de Rural \\ Pernambuco (UFPE) Rua D. Manoel de Medeiros, s/n - Dois Irmãos - CEP: 52171-900 \\ - Recife - PE - Brasil \\ tscs@cin.ufpe.br, \{amanda.calixto2, jeane.ufrpe\}@gmail.com
}

\begin{abstract}
Resumo. $O$ aplicativo proposto no presente trabalho, Adoletras, se propõe a auxiliar no processo de alfabetização de crianças na faixa etária entre 6 e 7 anos. $O$ Adoletras permite trabalhar a grafia das palavras e das sílabas que as compõem de forma lúdica, promovendo uma Aprendizagem Significativa, uma vez que os elementos do jogo estão presentes nos ambientes comuns ao universo infantil. Adicionalmente, o Adoletras possui recursos de Realidade Aumentada, levando a uma interação entre objetos concretos que compõem o jogo e os ambientes virtuais exibidos na tela do celular, estimulando a imaginação e corroborando para a construção do conhecimento nos aprendizes.
\end{abstract}

\section{Cenário de uso}

A alfabetização consiste em um conjunto de habilidades desenvolvidas que permitem decodificar, compreender e utilizar um sistema de símbolos, representados por alfabeto, números e ícones, permitindo que o indivíduo leia e escreva em uma determinada língua.

Pesquisas realizadas pelo o Instituto Brasileiro de Geografia e Estatística (IBGE) em 2015, indicam que existe no Brasil cerca de 13 milhões de pessoas, acima de 15 anos, que são analfabetas, correspondendo a 8,7\% de nossa população. Ao considerarmos o letramento, ou seja, a capacidade de compreensão e interpretação textual, os dados do IBGE indicam que $27 \%$ da população adulta brasileira não atingem 
VI Congresso Brasileiro de Informática na Educação (CBIE 2017)

Anais dos Workshops do VI Congresso Brasileiro de Informática na Educação (WCBIE 2017)

um nível satisfatório de alfabetização funcional, sendo que o problema da má alfabetização se desencadeia desde as séries iniciais, isto é, desde a alfabetização infantil (Santos, 2016).

Dentre os fatores que podem corroborar para o analfabetismo nas séries iniciais, pode-se citar metodologia aplicada, sendo necessária portanto uma escolha criteriosa do método a ser empregado. Considerando a educação infantil, a alfabetização se dá a partir da interação da criança com os objetos, a execução de sequências de ações e experiências vividas (Rodrigues, 2013). Segundo Silviane Barbato (Barbato, 2008), as crianças constroem seu conhecimento utilizando procedimentos lúdicos tais como brincadeiras livres ou planejadas, elaboradas pelos professores com uma finalidade didática, sendo a imaginação um elemento diferencial neste processo.

Vygotsky (2007) afirma que a criança, ao brincar, relaciona situações vividas com atitudes imaginárias. Essa interação entre a realidade e a imaginação propiciam uma série de possibilidades de interpretação, expressão e ação pela criança.

Para Vygotsky (2007), objetos ou ações são denotados como símbolos de primeira ordem. Para que a criança alcance o nível de criação de sinais escritos representativos dos símbolos falados das palavras, denotados símbolos de segunda ordem, é necessário que ela descubra que pode "desenhar a fala" da mesma forma que deseja objetos. Desta forma a criança aprenderia a ler e a escrever da mesma forma que aprende a falar (Vygotsky, 1998). Ainda no processo de alfabetização, além da percepção de que os sons têm uma representação gráfica, é necessário distinguir os sons da fala, aprendendo a isolá-los e distingui-los uns dos outros (Lemle, 2003).

Segundo Rodrigues (2013), o jogo corrobora com o processo de aprendizagem lúdica na alfabetização. As decisões, desafios, solução de conflitos, entre outros, promove a construção do pensamento na criança, levando-a a adquirir novos conhecimentos e ativando sua imaginação, contribuindo para uma aprendizagem prazerosa. Rodrigues firma ainda que os jogos permitem que as crianças desenvolvam, dentre outros, a representação do mundo, a linguagem, bem como a leitura e a escrita. Tais elementos promovem uma aprendizagem lúdica e corroboram para uma aprendizagem significativa, a qual caracteriza-se pela interação entre o cognitivo individual e as novas informações, as quais são ancoradas com os conceitos mais relevantes e inclusivos dos aprendizes modificando, assim, sua estrutura cognitiva inicial.

Veen e Vrakking (2009) afirmam que os Jogos Digitais também promovem o desenvolvimento de várias habilidades metacognitivas na aprendizagem, uma vez que levam ao desenvolvimento de estratégias e soluções para as dificuldades.

Em um estudo recente, Pizarro (2012) afirma que os jogos digitais podem auxiliar no processo de alfabetização e apresenta uma lista de jogos que podem ser 
VI Congresso Brasileiro de Informática na Educação (CBIE 2017)

Anais dos Workshops do VI Congresso Brasileiro de Informática na Educação (WCBIE 2017)

usados para este fim.

O jogo Alfabeto, desenvolvido em flash, por exemplo, permite que o aluno relacione a letra inicial com o elemento ilustrado em uma figura relacionado, o som da letra à sua grafia, relacionando-os com a gravura. Um outro jogo que permite identificar a grafia e a sonoridade das letras é o Alfabeto de Sabão, onde as letras são exibidas em bolhas de sabão devendo o aprendiz buscá-las no teclado. Embora a maioria dos jogos pesquisados façam uma correspondência entre a primeira letra de uma palavra e gravuras correspondentes, o estudo também traz exemplos que buscam trabalhar as sílabas, tais como Ludo Primeiros Passos, um jogo de etapas onde a correspondência silábica é feita na terceira fase, onde o jogador busca completar uma palavra com a sílaba que está faltando e, na quarta e última fase, onde as sílabas aparecem embaralhadas e o jogador deve colocá-las em ordem, de modo a formar a palavra correspondente à gravura.

Sistemas computacionais podem ainda promover a interação do mundo virtual com o mundo real, através de uma tecnologia denominada Realidade Aumentada (RA). Embora a Realidade Aumentada venha sendo desenvolvida e empregada desde a década de 90, a possibilidade de interação com objetos do mundo real tem motivado recentemente sua inclusão em abordagens educacionais (Moura, 2012).

Há abordagens voltadas para a alfabetização de crianças que lançam mão de elementos de RA. O aplicativo AlfabetoKinect, proposto por Alves et al (2012) é um exemplo disto. $\mathrm{O}$ aplicativo promove a aprendizagem do alfabeto utilizando $\mathrm{O}$ mapeamento corporal do dispositivo Kinect de modo a reconhecer gestos e a comunicação verbal do usuário, cujo objetivo é associar uma letra à imagem do objeto e a uma palavra, movimentando-os para posições específicas da tela. O software verifica no final se a correspondência foi feita de forma correta.

Os jogos, portanto, podem promover a aprendizagem e o desenvolvimento dos alunos na práticas escolares, sendo uma ferramenta importante para auxiliar o processo de alfabetização quando associado às demais estratégias de ensino (Kishimoto, 2003).

Buscando proporcionar uma melhor experiência de aprendizagem e percebendo a potencialidade da técnica em abordagens educacionais, o aplicativo Adoletras aqui proposto lança mão de recursos de Realidade Aumentada em um jogo voltado para a alfabetização de crianças, considerando que esta potencializa a linha proposta por Vygotsky (2007), promovendo a interação entre a realidade e o mundo virtual, o qual estimula a imaginação das crianças. $O$ jogo corrobora para uma aprendizagem significativa, visto que, lança mão de cenários que fazem parte do universo infantil, tais como: parque, praia e zoológico, fazendo que a criança crie constructos referentes à leitura, escrita e sonoridade das sílabas relacionando-os com elementos que lhe são familiares. 
VI Congresso Brasileiro de Informática na Educação (CBIE 2017)

Anais dos Workshops do VI Congresso Brasileiro de Informática na Educação (WCBIE 2017)

\section{Desenvolvimento}

Para o desenvolvimento deste protótipo foi criado um Game Design Document (GDD), que é um documento que engloba todos os elementos, tanto conceituais quanto tecnológicos, que estruturam um projeto de jogo. O GDD é utilizado pela equipe para consultar os objetos que compõem o jogo, quais seus atributos e como eles se relacionam (Schuytema, 2008).

O jogo para dispositivos móveis foi criado utilizando a engine Unity com o framework Vuforia para sistemas Android com versão mínima 4.2, a linguagem de programação usada foi $\mathrm{C \#}$.

O processo de desenvolvimento do jogo utilizou o wireframe, que é definido como um guia visual básico da Interface de Usuário. Ainda foi criado o fluxo do jogo com o intuito de nortear o seu desenvolvimento (Figura 1). Este fluxo apresenta as telas e informação de como será a interação do jogador com o game. Adicionalmente, a Figura 1 mostra informações sobre a condição de vitória e derrota do jogador no game. O jogo em sua versão de protótipo utilizará a licença freeware, podendo ser distribuído gratuitamente, mas não pode ser modificado.

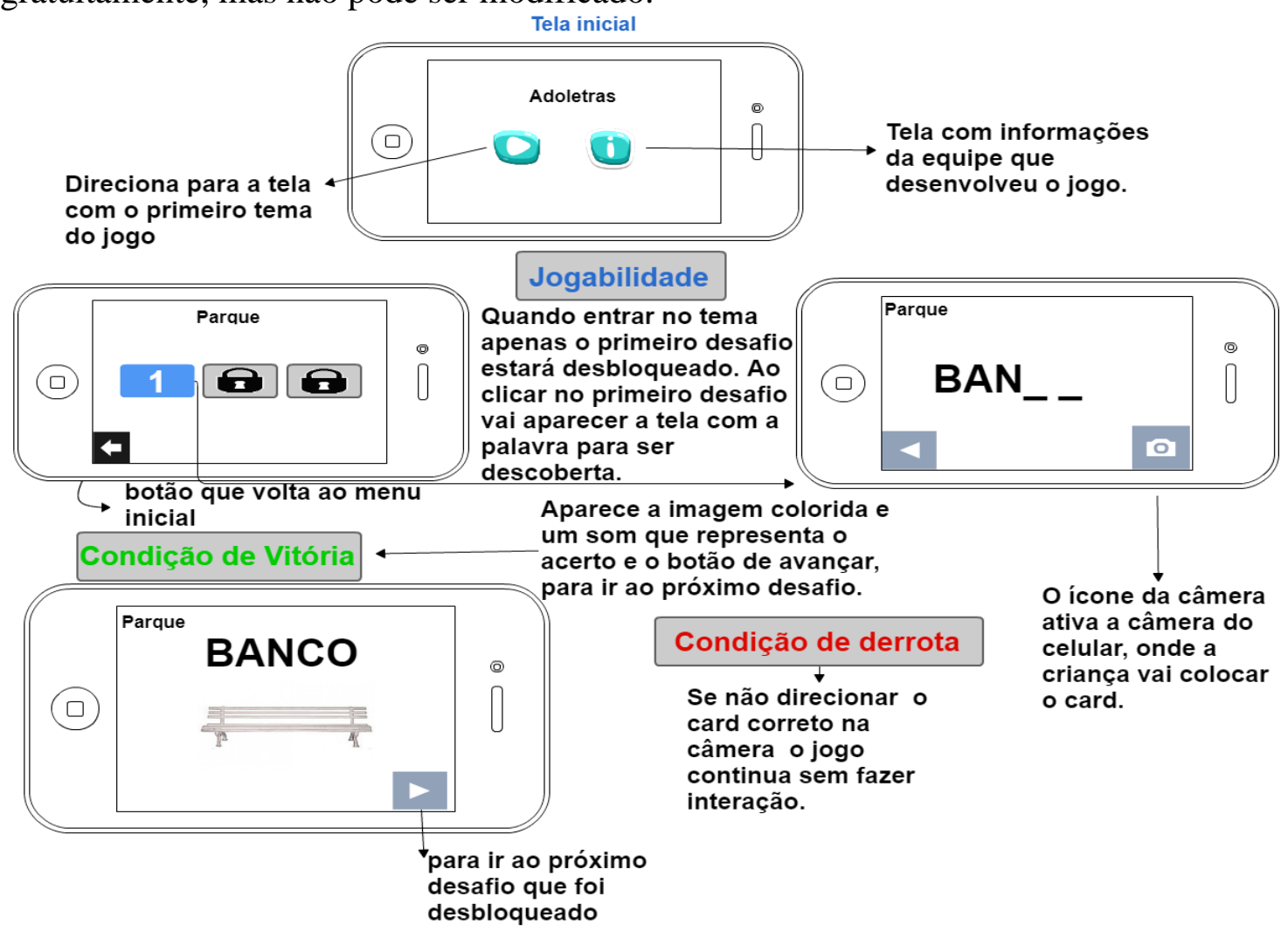

Figura 1. Fluxo do Jogo 
VI Congresso Brasileiro de Informática na Educação (CBIE 2017)

Anais dos Workshops do VI Congresso Brasileiro de Informática na Educação (WCBIE 2017)

\section{Apresentação do Software}

O aplicativo Adoletras, Figura 2(a), consiste em um jogo cujo protótipo atual envolve três estágios, voltado preferencialmente para crianças na faixa etária de 6 a 7 anos, sendo proposto como uma ferramenta para auxiliar no processo de alfabetização infantil. O Adoletras pode ser aplicado em diferentes estágios do processo de alfabetização, sendo necessário que os usuários tenham um nível de compreensão do sistema silábico-alfabético ou alfabético (Leal et al, 2005). O protótipo do jogo consiste do ambiente digital com referências presentes nesta fase da infância, de modo a promover a aprendizagem significativa, e de um conjunto de cartas ( $c a r d s)$ o qual será utilizado através de recursos de Realidade Aumentada.

O conjunto de cards que acompanha o jogo é uma forma de generalizar as palavras que estão sendo trabalhadas, podendo, com algumas adaptações, ser ampliado ou mesmo ser substituído por figuras e elementos presentes em um livro didático. Também considera-se a utilização de técnicas de reconhecimento de imagens de modo que o usuário possa capturar fotos dos objetos com a câmera de dispositivo móvel e o jogo faz a associação com a palavra correspondente.

Em sua versão atual, o Adoletras engloba três fases: Parque, Zoológico e Praia. A cada fase está associado um conjunto de palavras e ações referentes a elementos encontrados nos diferentes cenários. As fases indicam ambientes que fazem parte do universo lúdico infantil, e, em cada um deles há um conjunto de estágios, nos quais a criança será levada a resolver desafios envolvendo a grafia de palavras. Cada estágio está associado a um conjunto de cards físicos, os quais são utilizados para responder os desafios ali propostos. O fluxo do jogo encontra-se descrito na Figura 1.

A fase Parque, Figura 2(b), consiste de três estágios, nos quais serão trabalhadas as palavras escorregador, gangorra e patinete. Os desafios são propostos em um nível crescente de dificuldade. Para a palavra escorregador, por exemplo, inicialmente é exibida na tela do celular a palavra escorregador. A criança escolhe um dos cards e o posiciona na frente da câmera do celular. Se a sombra corresponder ao elemento escorregador, é emitido um som representando que a resposta está correta e, no card, vai aparecer a imagem colorida do escorregador e o botão de avançar, para ir ao próximo desafio. Caso o card não corresponda ao elemento não vai haver mensagem com feedback, apenas se a resposta for a correta. Desafios similares são propostos para as palavras gangorra e patinete, sendo que a cada uma delas corresponde um conjunto diferente de cards, dentre os quais a criança realiza a escolha.

Na fase Zoológico o nível de dificuldade é incrementado. São trabalhadas as palavras leão, cobra, girafa, tucano, elefante, macaco e hipopótamo. A criança poderá ser levada a preencher as sílabas para completar as palavras e assim associá-las às figuras correspondentes, sons emitidos pelos animais ou descobrir a palavra 
VI Congresso Brasileiro de Informática na Educação (CBIE 2017)

Anais dos Workshops do VI Congresso Brasileiro de Informática na Educação (WCBIE 2017)

correspondentes às figuras. Por exemplo, ao trabalhar a palavra leão, aparecerá na tela do celular : _ _ ão e a sombra da imagem de um leão. Ao posicionar o card correto em frente à câmera, é emitido um som representando que a resposta está correta, bem como a imagem colorida do leão. A fase Zoológico apresenta outros tipos de desafios. Por exemplo, para a palavra cobra aparecerá na tela do celular a sombra da imagem de uma cobra e o som de seu silvar. Ao posicionar o card correto em frente à câmera é emitido um som representando que a resposta está correta, bem como a imagem colorida da cobra.

Na terceira fase, denominada Praia, são trabalhadas palavras relacionadas com este ambiente: areia, ondas concha, coco, barco, peixe, coqueiro, caranguejo e guardasol. O nível de dificuldade é aumentado em relação às demais fases, e a criança trabalhará também a abstração. Por exemplo, a palavra areia é exibida na tela do celular. Ao posicionar o card correspondente em frente à câmera é emitido, juntamente com a imagem colorida da areia, um som representando que a resposta está correta. Um outro tipo de desafio é apresentado para a palavra Coco. Ao posicionar o card correto em frente à câmera é emitido um som representando que a resposta está correta, bem como a imagem colorida do Coco.

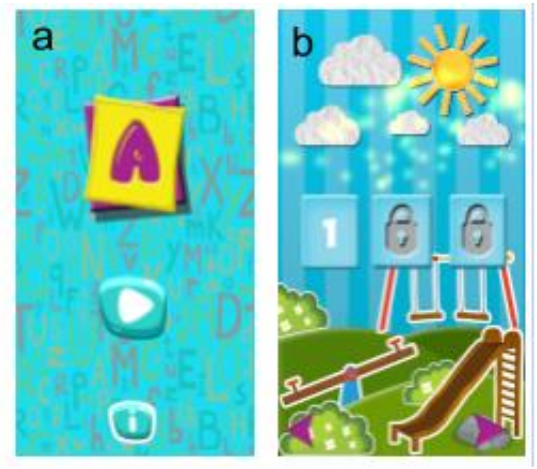

Figura 2. (a) Tela Inicial do Jogo e (b) Estágio do Parque

\section{Considerações finais}

O aplicativo Adoletras proposto no presente trabalho é uma ferramenta que pode auxiliar no processo de alfabetização infantil, sendo mais indicado para crianças na faixa etária de 6 a 7 anos de idade, levando em consideração que nesta fase o conhecimento é construído também de forma lúdica (Barbato, 2008). O jogo corrobora com esse processo, uma vez que os desafios, decisões e soluções apresentadas promove a construção do pensamento dos aprendizes nesta fase (Rodrigues, 2013).

Buscando promover uma Aprendizagem Significativa, o Adoletras apresenta os diferentes níveis de desafios em ambientes familiares ao universo infantil: Parque, Zoológico e Praia, considerando que o processo de alfabetização envolve a interação da 
VI Congresso Brasileiro de Informática na Educação (CBIE 2017)

Anais dos Workshops do VI Congresso Brasileiro de Informática na Educação (WCBIE 2017)

criança com objetos, a execução de sequências de ações e experiências vividas (Rodrigues, 2013).

Recursos de Realidade Aumentada também são encontrados no Adoletras. A Realidade Aumentada vem sendo introduzida em abordagens educacionais (Moura, 2012) e, para a faixa etária ao qual o jogo se destina, a RA permitiu a introdução de elementos concretos, os cards, que propiciam uma interação com o mundo virtual apresentado nos ambientes, estimulando a imaginação das crianças e corroborando para promover a aprendizagem (Vygotsky, 2007).

O jogo encontra-se em fase de prototipagem, sendo previstos testes de usabilidade os quais nortearão elementos tais como tamanho dos cards e interface. Como trabalhos futuros, pretende-se acrescentar outros ambientes familiares ao universo infantil, ampliando o número de fases, as palavras trabalhadas e sua sonoridade e os tipos de desafios, incluindo, por exemplo, o limite de tempo para apresentação das respostas. Uma diretiva considerada é utilizar técnicas de reconhecimento de imagens, de modo a capturar as fotos de objetos em ambientes reais e associá-los às palavras correspondentes. Com algumas adaptações os cards podem ser substituídos por figuras de um livro didático.

\section{Referências}

Alfabeto. Disponível em: <http://www.smartkids.com.br/jogo/alfabeto-em-flash>. Acesso em Junho de 2017.

Alfabeto de Sabão Disponível em: <.http://www.escolagames.com.br/jogos/alfabetoSabao/>. Acesso em Junho de 2017.

Alves, R.S., Araujo, J. O. A., Madeiro, F. (2012). AlfabetoKinect: Um aplicativo para auxiliar na alfabetização de crianças com o uso do Kinect. Simpósio Brasileiro de Informática na Educação-SBIE (Vol. 23, No. 1).

Barbato, S. B. (2008). Integração de crianças de 6 anos ao ensino fundamental. São Paulo: Parábola Editorial, 2008

Boulic, R.,Renault, O. (1991) “3D Hierarchies for Animation”, In: New Trends in Animation and Visualization, Edited by Nadia Magnenat-Thalmann and Daniel Thalmann, John Wiley \& Sons ltd., England.

Dyer, S., Martin, J., Zulauf, J. (1995) "Motion Capture White Paper", http://reality.sgi.com/employees/jam_sb/mocap/MoCapWP_v2.0.html, December.

Escola Games. http://www.escolagames.com.br/jogos/alfabetoSabao/ Acesso em junho de 2017.

Holton, M., Alexander, S. (1995) "Soft Cellular Modeling: A Technique for the 
VI Congresso Brasileiro de Informática na Educação (CBIE 2017)

Anais dos Workshops do VI Congresso Brasileiro de Informática na Educação (WCBIE 2017)

Simulation of Non-rigid Materials", Computer Graphics: Developments in Virtual Environments, R. A. Earnshaw and J. A. Vince, England, Academic Press Ltd., p. 449-460.

IBGE

Disponível

em: http://www.ibge.gov.br/home/estatistica/populacao/estimativa2015/default.shtm Acesso em junho de 2017

Knuth, D. E. (1984), The TeXbook, Addison Wesley, 15th edition.

Kishimoto, T. (2003). Jogo, brinquedo, brincadeira e a educação, Cortez, SP, $7^{\mathrm{a}}$ ed.

Leal, T., Albuquerque, E. B., Leite, T. M. R.(2005) Jogos: alternativas didáticas para brincar alfabetizando. Belo Horizonte: Autêntica.

Lemle, M. (2003), Guia teórico do alfabetizador. São Paulo, SP: Ática.

Ludo Primeiros Passos. Disponível em: <http://portal.ludoeducativo.com.br/pt/play/ludo-primeiros-passos〉. Acesso em junho de 2017.

Moura, A. (2012). Mobile Learning: Tendências tecnológicas emergentes. In Aprender na era digital: Jogos e Mobile-Learning, 127 - 147. . Santo Tirso: De Facto Editores

Pizarro, E. M. B. (2012). Jogo Digital: Um auxílio no processo de alfabetização. UFRGS

Rodrigues, L. S. (2013). Jogos e brincadeiras como ferramentas no processo de aprendizagem lúdica na alfabetização, MSC

Santos, S. C. (2016). Análise de Métodos de Alfabetização em Séries Iniciais, TCC, UFG, Faculdade de Letras.

Schuytema, P. Design de games: uma abordagem prática. Cengage Learning, 2008.

Smith, A. and Jones, B. (1999). On the complexity of computing. In Advances in Computer Science, pages 555-566. Publishing Press.

Veen, W. and Vrakking, B. (2009) Homo Zappiens: Educando na Era Digital. Porto Alegre, Artmed.

Vygotsky, L.S. (2007) A formação social da mente. São Paulo: Martins Fontes.

Vygotsky, L.S. (1998) A formação social da mente: o desenvolvimento dos processos psicológicos superiores. São Paulo: Martins Fontes. 